\title{
Coinfection of hepatitis A virus genotype IA and IIIA complicated with autoimmune hemolytic anemia, prolonged cholestasis, and false-positive immunoglobulin $M$ anti-hepatitis E virus: a case report
}

\author{
Hee-Sup Kim¹, Sook-Hyang Jeong ${ }^{1}$, Je-Hyuck Jang ${ }^{1}$, Hyung-Joon Myung ${ }^{1}$, Jin-Wook Kim¹, \\ Soo-Mee Bang ${ }^{1}$, Sang Hoon Song ${ }^{2}$, Haeryoung $\mathrm{Kim}^{3}$, and Hae Sun Yun ${ }^{4}$ \\ ${ }^{1}$ Departments of Internal Medicine, ${ }^{2}$ Laboratory Medicine, and ${ }^{3}$ Pathology, Seoul National University Bundang Hospital, \\ Seoul National University College of Medicine, Seongnam; ${ }^{4}$ Division of Enteric and Hepatitis Viruses, Center for \\ Infectious Diseases, Korea National Institute of Health, Seoul, Korea
}

\begin{abstract}
A 37-year-old male presented with fever and jaundice was diagnosed as hepatitis A complicated with progressive cholestasis and severe autoimmune hemolytic anemia. He was treated with high-dose prednisolone $(1.5 \mathrm{mg} / \mathrm{kg})$, and eventually recovered. His initial serum contained genotype IA hepatitis A virus (HAV), which was subsequently replaced by genotype IIIA HAV. Moreover, at the time of development of hemolytic anemia, he became positive for immunoglobulin $M(I g M)$ anti-hepatitis E virus (HEV). We detected HAV antigens in the liver biopsy specimen, while we detected neither HEV antigen in the liver nor HEV RNA in his serum. This is the first report of hepatitis A coinfected with two different genotypes manifesting with autoimmune hemolytic anemia, prolonged cholestasis, and false-positive IgM anti-HEV. (Korean J Hepatol 2011;17:323-327)
\end{abstract}

Keywords: Hepatitis A virus; Genotype; Coinfection; Hemolytic anemia; Korea

\section{INTRODUCTION}

Hepatitis A virus (HAV) remains an important causative agent of acute viral hepatitis, causing large outbreak or severe cases of fulminant hepatitis with fatal outcomes. Acute hepatitis A can be complicated by extrahepatic manifestations, including hemolytic anemia, aplastic anemia, acute renal failure, and acute reactive arthritis. ${ }^{1,2}$

Although HAV displays only a single serotype, seven HAV genotypes have been identified: four genotypes (I, II, III and VII) are of human origin, and other three (IV, V, VI) are of simian origin. HAV genotypes have unique geographic distributions; however, co-circulation of multiple genotypes or subgenotypes has been reported in some regions of world. ${ }^{3}$

This report presents a peculiar coinfection hepatitis with the HAV genotype IA and IIIA, complicated by severe autoimmune hemolytic anemia and prolonged cholestasis, along with coexistence of IgM anti-hepatitis E virus (HEV). We performed immunohistochemical staining of HAV antigen and HEV antigen in the liver biopsy specimen, and molecular detection of HAV RNA and HEV RNA in the serial serum samples obtained from the patient.

Received November 8, 2010; Revised July 12, 2011; Accepted July 26, 2011

Abbreviations: AIHA, autoimmune hemolytic anemia; anti-IgG, immunoglobulin G antibody; ALT, alanine aminotransferase; AST, aspartate aminotransferase; HAV, Hepatitis A virus; Hb, hemoglobin; HCV, Hepatitis C virus; HEV, Hepatitis E virus; HAV RNA, hepatitis A virus ribonucleic acid; HEV RNA, hepatitis E virus ribonucleic acid; IgM anti-HAV, immunoglobulin M antibody to hepatitis A virus; IgM anti-HBc, immunoglobulin $\mathrm{M}$ antibody to hepatitis $\mathrm{B}$ core antigen; IgM anti-HEV, immunoglobulin $\mathrm{M}$ antibody to hepatitis $\mathrm{E}$ virus; INR, international normalized ratio; $\gamma$-GT, gamma-glutamyl transpeptidase

Comesponding author: Sook-Hyang Jeong

Department of Internal Medicine, Seoul National University Bundang Hospital, 166 Gumi-ro, Bundang-gu, Seongnam 463-707, Korea Tel. +82-31-787-7039, Fax. +82-31-787-7042, E-mail; jsh@snubh.org 


\section{CASE REPORT}

A 37-year-old male visited the emergency room on December 28,2008 for treatment of fever $\left(40^{\circ} \mathrm{C}\right)$, chills, and jaundice lasting for 2 days. He was a nonsmoking social drinker, and denied recent overseas travel, contact with hepatitis cases, or taking any medications. His past medical history revealed an episode of pneumonia and bronchiectasis that occurred 20 years earlier. Physical examination showed a temperature of $40^{\circ} \mathrm{C}$ and mild icterus without hepatosplenomegly. Results from chest and throat examination were normal without cervical lymphadenopathy. His initial level of aspartate transaminase (AST) was 12,000 IU/L, alanine aminotransferase (ALT) 8,129 IU/L, total bilirubin $4.5 \mathrm{mg} / \mathrm{dL}$, prothrombin time 23.6 second (international normalized ratio 2.06) and hemoglobin (Hb) $14.3 \mathrm{~g} / \mathrm{dL}$. IgM anti-HAV (Microparticle Enzyme immunoassay, Abbott, Wiesbaden, Germany) and IgG anti-HAV (Radio-immunoassay kit, General Biologicals corp., Taiwan) were both positive. Hepatitis B virus surface antigen, IgM anti-HBc, hepatitis $\mathrm{C}$ virus (HCV) RNA, and anti-HCV were all negative. IgM anti-HEV (Genelabs Diganostics, Singapore) was negative. Chest X ray and CT scan of the abdomen and chest showed no remarkable findings. Under diagnosis of acute hepatitis A, the patient received supportive care showing gradual recovery, and AST/ALT levels decreased to 285/919 IU/L, with a stable hemoglobin level of $14.4 \mathrm{~g} / \mathrm{dL}$, while his total bilirubin level progressively increased up to $21.8 \mathrm{mg} / \mathrm{dL}$ at hospital discharge (January 6, 2009) suggesting a prolonged cholestatic feature.

On January 12, 2009, he was readmitted for recurrent fever, general weakness, and aggravated jaundice. At this time, IgM anti-HEV was positive with persistently positive IgM anti-HAV. Total and direct bilirubin levels were $39 \mathrm{mg} / \mathrm{dL}$ and $29 \mathrm{mg} / \mathrm{dL}$, respectively, with an alkaline phosphatase level of $374 \mathrm{IU} / \mathrm{L}$, and $\mathrm{Hb}$ level was $13.4 \mathrm{~g} / \mathrm{dL}$. Until January 24 , total bilirubin level increased rapidly, up to $64.1 \mathrm{mg} / \mathrm{dL}$ (direct bilirubin level of $41 \mathrm{mg} / \mathrm{dL}$ ), and $\mathrm{Hb}$ level fell rapidly to $5.5 \mathrm{~g} / \mathrm{dL}$, despite decreasing levels of transaminase. Serial laboratory results are summarized in Table 1. Haptoglobin level was $27.3 \mathrm{mg} / \mathrm{dL}$ and direct Coombs' test was positive (anti-IgG type) with polychromasia and anisocytosis on a blood film (Fig. 1A), which was compatible with autoimmune hemolytic anemia (AIHA). IgM anti-parvovirus B19 was negative.

Oral prednisolone therapy $(1 \mathrm{mg} / \mathrm{kg})$ was started on January 22, however, his reticulocyte count remained low $(0.13 \%)$, and he received 17 units of red blood cell transfusion for 11 days. To exclude the possibility of pure red cell aplasia, bone marrow aspiration and biopsy were performed, and it showed increased erythropoiesis compatible with AIHA without evidence of pure red cell aplasia (Fig. 1B). The dosage of oral prednisolone therapy was incremented to $1.5 \mathrm{mg} / \mathrm{kg} / \mathrm{day}$, and after 8 days of the

Table 1. Hematologic and biochemical findings of the case

\begin{tabular}{|c|c|c|c|c|c|c|c|c|}
\hline & $2008 / 12 / 28$ & $2009 / 1 / 6$ & 2009/1/12 & 2009/1/19 & $2009 / 1 / 24^{*}$ & $2009 / 2 / 12^{\dagger}$ & $2009 / 2 / 20^{+}$ & $2009 / 4 / 22$ \\
\hline Hemoglobin, g/dL & 14.3 & 14.4 & 11.2 & 7.6 & 5.5 & 10 & 12.1 & 14.3 \\
\hline Reticulocyte, \% & & & & 0.13 & 0.31 & 7.49 & 2.22 & \\
\hline Total bilirubin, $\mathrm{mg} / \mathrm{dL}$ & 4.5 & 21.8 & 34.2 & 37.8 & 39.3 & 10 & 5.4 & 0.7 \\
\hline AST, IU/L & $>12000$ & 285 & 79 & 76 & 154 & 90 & 22 & 21 \\
\hline $\mathrm{ALT}, \mathrm{IU} / \mathrm{L}$ & 8129 & 919 & 138 & 88 & 130 & 380 & 136 & 49 \\
\hline$\gamma-\mathrm{GT}, \mathrm{IU} / \mathrm{L}$ & 349 & 448 & 350 & 325 & 552 & 1482 & 897 & \\
\hline Albumin, $\mathrm{g} / \mathrm{dL}$ & 3.7 & 3.2 & 3.6 & 3.0 & 3.1 & 3.8 & 3.8 & 3.8 \\
\hline Prothrombin time, INR & 1.69 & 1.06 & 1.04 & 1.03 & 1.08 & 0.90 & 0.90 & \\
\hline \multicolumn{9}{|l|}{ HAV RNA } \\
\hline in plasma & & & IA & & IA & ND & & IIIA \\
\hline in stool & & & IA & & IA & ND & & ND \\
\hline \multicolumn{9}{|l|}{ HEV RNA } \\
\hline in plasma & & & ND & & & ND & & \\
\hline in stool & & & ND & & & ND & & \\
\hline
\end{tabular}

$\mathrm{ND}$, not detected.

* Prednisolone $75 \mathrm{mg}$ per day started on this day, ${ }^{\dagger}$ Liver biopsy was performed during therapy with prednisolone $105 \mathrm{mg}$ per day,

* Discharge day on prednisolone $75 \mathrm{mg}$ per day administration.

AST, aspartate aminotransferase; ALT, alanine aminotransferase; HAV, Hepatitis A virus; HEV, Hepatitis E virus; ND, not detected. 

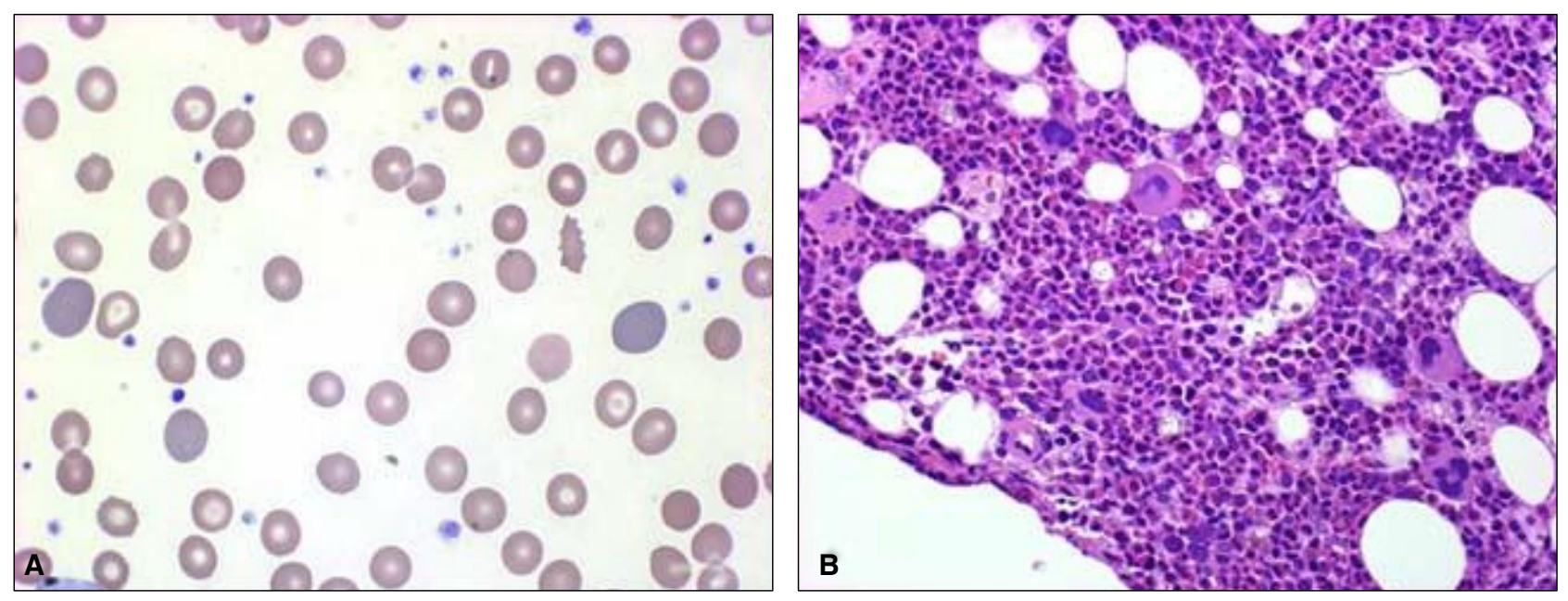

Figure 1. (A) Peripheral blood smear showing marked polychromasia and anisocytosis (Wright-Giemsa stain, $\times 1,000$ ). (B) Photomicrographs of a bone marrow biopsy section showing increased erythropoiesis [hematoxylin and eosin stain (H\&E), $\times 400]$.
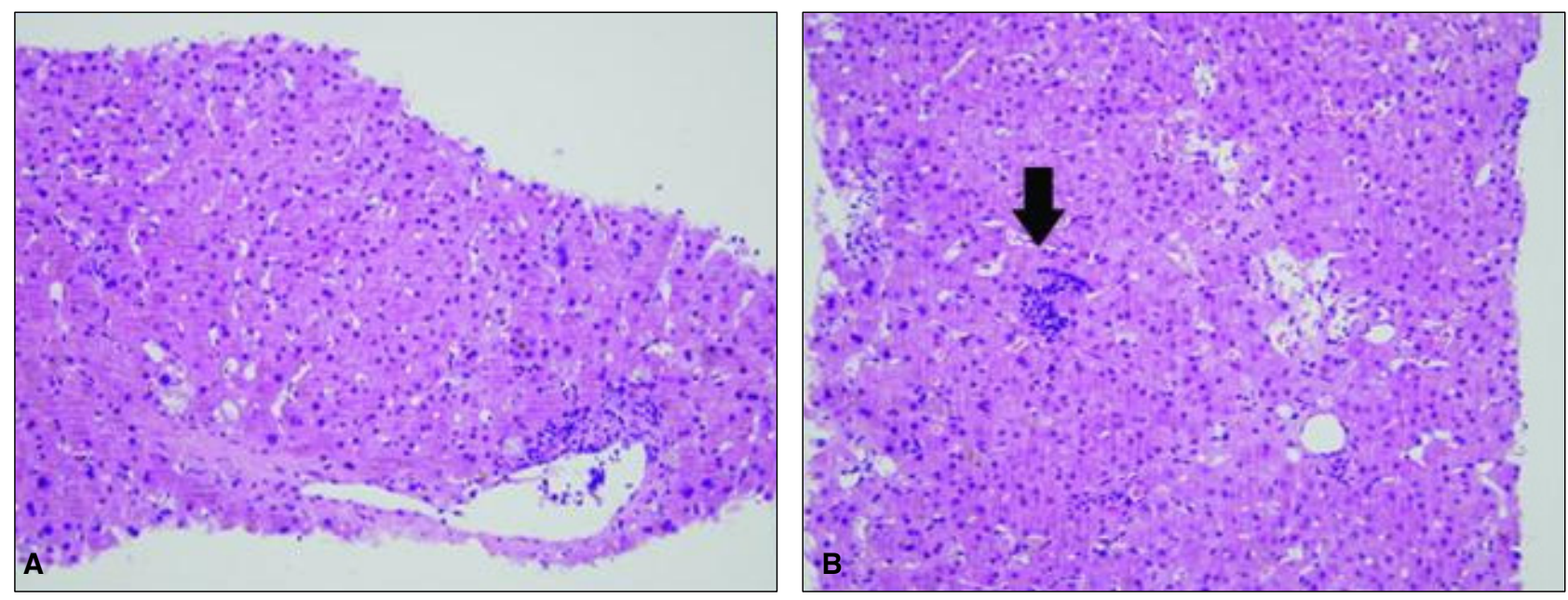

Figure 2. The liver biopsy specimen exhibited hepatocellular and canalicular cholestasis, hepatocyte ballooning, and lobular spotty necrosis, consistent with cholestatic hepatitis. Extramedullary hematopoiesis was also seen (arrow; H\&E, ×200).
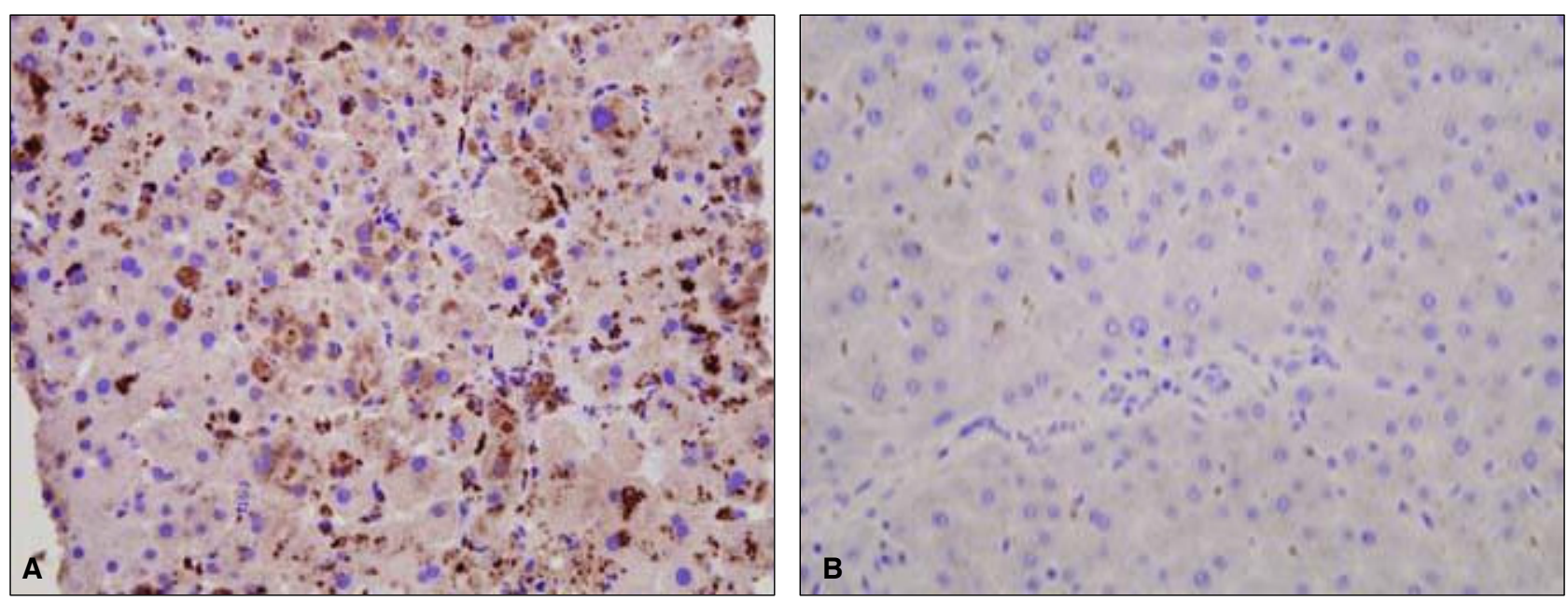

Figure 3. Immunohistochemical staining of the liver biopsy specimen. Strong cytoplasmic staining for hepatitis A virus antigen was noted in our case (A), whereas staining was absent in a case of chronic hepatitis B (B) as a negative control (A and B, $\times 400)$. 
incremental dose therapy, the patient became gradually transfusion-independent with increase of $\mathrm{Hb}$ level to 12.1 $\mathrm{g} / \mathrm{dL}$. Liver function tests showed AST of $22 \mathrm{IU} / \mathrm{L}$, ALT 136 IU/L, alkaline phosphatase $285 \mathrm{IU} / \mathrm{L}$, gamma-glutamyl transferase (GGT) $897 \mathrm{IU} / \mathrm{L}$, and total bilirubin of $5.4 \mathrm{mg} / \mathrm{dL}$.

To exclude the possibility of fibrosing cholestatic hepatitis associated with immunosuppressive therapy, percutaneous liver biopsy was undertaken on February 12, which revealed hepatocellular and canalicular cholestasis, hepatocyte ballooning, and lobular spotty necrosis compatible with cholestatic hepatitis and extramedullary hematopoiesis (Fig. 2). Immunohistochemical staining was performed for detection of HAV antigens and HEV antigens using HAV antibody (Purified HAV, Abcam, Cambridge, UK; mouse monoclonal, 1:50) and HEV antibody (Abbiotec, CA, USA; 1:200), respectively. Strong cytoplasmic staining for HAV was noted, whereas staining was absent in specimens used for negative control (Fig. 3). In this case, there was no staining for HEV antigen (data not shown).

After a 2 month-period of gradual tapering of prednisolone, complete recovery of liver function was achieved at 5 months after the patient's initial admission. However, his IgM anti-HAV was positive until May 29, while both IgM antiHEV and IgG anti-HEV (Genelabs Diganostics, Singapore) were negative.

During the course of his illness, serial serum samples were available for detection of HAV RNA and HEV RNA, according to the method described in previous studies. ${ }^{4}$ All HAV RNA-positive samples were sequenced using the BigDye Terminator (ABI Prism 377 automatic sequencer, Toroed, Norway). Interestingly, initial HAV detected on January 14, 2009 was genotype IA, which was subsequently replaced by HAV genotype IIIA during the later phase of the illness (April 22, 2009), while HEV RNA was not detected by Okamoto's method, as previously reported. ${ }^{5,6}$

\section{DISCUSSION}

This report described a case of acute viral hepatitis coinfected by HAV genotype IA and genotype IIIA complicated with severe autoimmune hemolytic anemia, prolonged cholestasis, and coexistence of IgM anti-HEV, which was successfully treated by high dose $(1.5 \mathrm{mg} / \mathrm{kg} /$ day $)$ prednisolone therapy.

There have been a few reports of severe Coombs-positive AIHA with or without pure red cell aplasia, complicating acute viral hepatitis. ${ }^{7}$ However, coinfection of HAV genotype IA and IIIA complicated with severe AIHA has not been reported. Genotype 1A HAV was a major genotype in Korea, however, during recent nationwide outbreak of hepatitis A, a rapid genotypic shift from genotype IA to IIIA has occurred. ${ }^{4,8}$ Therefore, at least two genotypes of HAV co-circulate in Korea.

Coinfection of the HAV genotype IA and IIIA was a peculiar finding in this case. From onset of symptoms to development of AIHA, HAV genotype IA was consistently detected in the patient's plasma and stool. Subsequently, during prolonged follow-up, his HAV genotype was replaced from genotype IA to IIIA. This replacement can be explained by initially mixed infection of HAV genotype IA and IIIA with a dominant population of HAV genotype IA and reciprocal inhibition of genotype IIIA. During his initial hepatitis course, vigorous immune responses may have controlled HAV genotype IA up to an undetectable level, and subsequent strong immunosuppression for the treatment of hemolytic anemia may support replication of HAV genotype IIIA, a minor population. To our knowledge, this is the first case of coinfection of hepatitis A genotype IA and IIIA documented. Coppola et $\mathrm{al}^{9}$ reported a case of acute hepatitis A complicated with prolonged cholestasis and coinfection of genotype IA and IB, and suggested that coinfection of two HAV subgenotypes may be a reason for prolonged cholestasis and viremia due to impairment of antibody production or neutralizing activity on the basis of the simultaneous antigenic stimulatory effect of the two HAV isolates. However, HAV has only one common serotype, and this finding was not supported by experimental data.

The interesting finding of this case was that IgM anti$\mathrm{HEV}$ at the first manifestation was negative, which turned out to be positive at the initiation of hemolytic anemia. Afterwards, the transiently positive result for IgM anti-HEV turned out to be negative, along with a negative result for IgG anti-HEV during the follow-up period. Both hepatitis A virus (HAV) and hepatitis E virus (HEV) infection can be transmitted by the fecal-oral route with similar incubation periods and clinical presentations. Among patients with sporadic acute viral hepatitis, cases showing simultaneously positive results for immunoglobulin $\mathrm{M}$ (IgM) anti-HAV and IgM anti-HEV have been reported, and were regarded as coinfection of HAV and HEV. ${ }^{10,11}$ However, HEV RNA was not detected in serum and stool samples, while HAV RNA 
was detected and genotyped. In immunohistochemical staining of liver biopsy specimens, HAV antigens showed strongly positive staining, in contrast to no staining for $\mathrm{HEV}$ antigens, although we were not able to obtain adequate positive control specimens. All of these results suggested the false positive reaction of initially positive IgM anti-HEV, rather than a true coinfection of HEV along with HAV. ${ }^{12}$ Severe cell necrosis associated with HAV infection may induce autoimmune reaction such as hemolytic anemia or autoimmune hepatitis. ${ }^{13,14}$ Nonspecific induction of IgM anti-HEV during massive hepatic necrosis death in the hepatitis phase of this case may be a possibility.

In conclusion, severe autoimmune hemolytic anemia and prolonged cholestasis can be complicated with acute hepatitis co-infected by HAV genotype IA and IIIA, which was successfully treated with high-dose prednisolone therapy. The coexistence of IgM anti-HEV in the setting of hepatitis A seems to be a false positive reaction rather than a true coinfection.

\section{REFERENCES}

1. Song KS, Kim MJ, Jang CS, Jung HS, Lee HH, Kwon OS, et al. Clinical features of acute viral hepatitis A complicated with acute renal failure. Korean J Hepatol 2007;13:166-173.

2. Schiff ER. Atypical clinical manifestations of hepatitis A. Vaccine 1992;10(Suppl 1):S18-S20.

3. Nainan OV, Xia G, Vaughan G, Margolis HS. Diagnosis of hepatitis a virus infection: a molecular approach. Clin Microbiol Rev 2006;19:
63-79.

4. Yun H, Kim S, Lee H, Byun KS, Kwon SY, Yim HJ, et al. Genetic analysis of HAV strains isolated from patients with acute hepatitis in Korea, 2005-2006. J Med Virol 2008;80:777-784.

5. Lin CC, Wu JC, Chang TT, Chang WY, Yu ML, Tam AW, et al. Diagnostic value of immunoglobulin $\mathrm{G}(\mathrm{IgG})$ and IgM anti-hepatitis $\mathrm{E}$ virus (HEV) tests based on HEV RNA in an area where hepatitis $\mathrm{E}$ is not endemic. J Clin Microbiol 2000;38:3915-3918.

6. Mizuo H, Suzuki K, Takikawa Y, Sugai Y, Tokita H, Akahane Y, et al. Polyphyletic strains of hepatitis E virus are responsible for sporadic cases of acute hepatitis in Japan. J Clin Microbiol 2002;40:3209-3218.

7. Chehal A, Sharara AI, Haidar HA, Haidar J, Bazarbachi A. Acute viral hepatitis A and parvovirus B19 infections complicated by pure red cell aplasia and autoimmune hemolytic anemia. J Hepatol 2002;37:163-165.

8. Byun KS, Kim JH, Song KJ, Baek LJ, Song JW, Park SH, et al. Molecular epidemiology of hepatitis A virus in Korea. J Gastroenterol Hepatol 2001;16:519-524.

9. Coppola N, Genovese D, Pisaturo M, Taffon S, Argentini C, Pasquale G, et al. Acute hepatitis with severe cholestasis and prolonged clinical course due to hepatitis A virus Ia and Ib coinfection. Clin Infect Dis 2007;44:e73-e77.

10. Zaki Mel S, Salama OS, Mansour FA, Hossein S. Hepatitis E virus coinfection with hepatotropic viruses in Egyptian children. J Microbiol Immunol Infect 2008;41:254-258.

11. Kang HM, Jeong SH, Kim JW, Lee D, Choi CK, Park YS, et al. Recent etiology and clinical features of acute viral hepatitis in a single center of Korea. Korean J Hepatol 2007;13:495-502.

12. Mast EE, Kuramoto IK, Favorov MO, Schoening VR, Burkholder BT, Shapiro $\mathrm{CN}$, et al. Prevalence of and risk factors for antibody to hepatitis E virus seroreactivity among blood donors in Northern California. J Infect Dis 1997;176:34-40.

13. Vento S, Garofano T, Di Perri G, Dolci L, Concia E, Bassetti D. Identification of hepatitis A virus as a trigger for autoimmune chronic hepatitis type 1 in susceptible individuals. Lancet 1991;337:1183-1187.

14. Huppertz HI, Treichel U, Gassel AM, Jeschke R, Meyer zum Büschenfelde KH. Autoimmune hepatitis following hepatitis A virus infection. J Hepatol 1995;23:204-208. 